\title{
Qualitative-quantitative analysis of narrative structures: The narrative roles of immigrants in Spanish television series*
}

\author{
XAVIER RUIZ COLLANTES, MATILDE OBRADORS, \\ EVA PUJADAS, JOAN FERRÉS, and ÓLIVER PÉREZ
}

\begin{abstract}
This paper presents a qualitative-quantitative method of analysis for semiotic narrative, applied to a case study of the image projected by immigrants in Spanish television series. The results contain five narrative prototypes in which immigrant characters tend to appear in Spanish television series. We consider the possible effects of recurring narrative settings on the construction of a public image of immigration in Spain.
\end{abstract}

Keywords: semiotics; narrative; immigration; television; series; fiction

\section{Introduction}

The study that we present in this paper is derived from a research project entitled "Television and the construction of a public image of immigration in Spain."

The basic premise of this work is that the world of television fiction, especially that part whose intention is to reflect a country's social realty, plays an important role in the creation of our images of specific social groups. Undoubtedly, the management of political, social, institutional, and cultural relationships between Spanish people and immigrants will be a fundamental issue in the nation's development in the next decades. The construction of fictitious worlds in a medium as influential as television will, in this sense, play a very relevant role. Television fiction does not only reflect reality. Above all, it projects and disseminates frameworks of reference, images, and stereotypes, which directly affect the way in which people experience social reality.

The figure of the immigrant is embodied in a series of characters appearing in different television series that reflect the presence of immigration in Spanish social life. Television series tend to introduce the figure of the immigrant in their narrative plots, thus making this figure visible in the fictional worlds they 
Table 1. Corpus of analysis

\begin{tabular}{llcc}
\hline Channel & Series & Number of plots & Number of plots per channel \\
\hline TVE 1 & Ana y los Siete & 1 & 1 \\
Antena 3 TV & Un paso adelante & 11 & 17 \\
& Policías & 5 & \\
Tele 5 & Código fuego & 1 & 23 \\
& El comisario & 12 & \\
& Hospital central & 4 & \\
& Javier ya no vive solo & 2 & \\
& Los Serrano & 3 & \\
& Siete vidas & 2 & \\
& & Total $=41$ & \\
\hline
\end{tabular}

represent. We should note that Spanish-produced series generally strive to reflect, in a realistic, dramatic or comical way, the worlds of everyday life in both professional and private contexts.

However, as will be seen, the visibility of the immigrant figure is not equal in each television channel, being subject to certain specific criteria.

\section{Corpus of analysis}

The corpus analyzed in this study comprises the serialized plots of Spanish productions containing at least one immigrant character which were broadcast during a complete season from September 2002 to September 2003. The statewide television channels included in the study are: La Primera (TVE 1) — with only one plot - and Tele 5 and Antena 3, which together have 41 narrative plots (adding up to 676 broadcasting minutes).

A significant fact is the practical absence of the figure of the immigrant in the series produced in Spain and broadcasted by Televisión Española (TVE) during the 2002-2003 season. In the context of the social world that this channel reflects in its fiction series, immigration in Spain is non-existent, thus making immigration invisible. Televisión Española restricts the treatment of topics related to immigration to news and magazine programmes. It is surprising that the only nationwide public television channel does not include in its fiction series the theme of immigration. Thus, Televisión Española does not seem to assume responsibility for establishing parameters regarding the diffusion of social and civic values for the subject of immigration through its television series.

In the 41 plots of the series analyzed, there are 29 characters representing immigrants. With regard to their general characterization, the predominance of characters from Latin America (15, approximately 50\%) should be noted. On 
the contrary, only one immigrant character comes from Maghrib, in contrast with the important presence of Maghribian immigrants in Spain. Also conspicuous by their absence are characters representing Asian immigrants. The rest of the characters come from the Near East (4), Sub-Saharan Africa (3), Eastern Europe (4) and Western Europe (2). In terms of physical features, no race clearly predominates over others, most of the characters are adults aged 18 to 40 and there is a slight predominance of men. Their psychological features and general behavior usually correspond to three fundamental variables: extroverts, charmers, and/or swindlers. In terms of their characteristic action framework, there is almost no public presence of immigrant characters, since they usually act in personal or professional spheres and almost never as social or political/institutional actors. Their most common jobs are in the services sector, illegal or semi-legal activities (crime, prostitution, etc.), and entertainment (circus, football, etc.).

Another point of interest is to what extent the character of the immigrant in television series produced by nationwide television channels is a regular character. In fact, these characters appear in the series within plots and sub-plots that run through several episodes of the fictional worlds presented. In this case, immigrants generally appear as peripheral and occasional characters.

This fact projects the image of a social reality in which the characters of foreign origin occupy a peripheral position and are not integrated in any stable way into the social life of the country. Moreover, bearing in mind that the regular characters in the series are those with which the viewer tends to identify, the absence of a regular role for immigrants in television fiction could be considered a symptom of the difficulty the Spanish viewer has in identifying with the immigrant. At the same time, it reveals a lack of willingness on the part of producers and scriptwriters to educate the viewer to identify with the figure of "the other," that person from another country and a different culture.

There is one exception to what we describe above. In the series "Un Paso Adelante" on Antena $3 \mathrm{TV}$, there is a regular character called Pavel who possesses some interesting features. He is a young black Cuban, a seducer who works in show-business. This is a prototypical figure in some respects. His Latin-American origin connects with a greater presence of Latin-Americans in television series compared with other types of immigrants; his characteristics connect with certain people who have become famous in Spain and who appear in the sensationalist press, magazines, and television talk shows. That is, this is a prototype of a character with a high media profile.

Based on this fact, we may establish a prospective hypothesis that the presence in nationwide television channels of immigrants as regular characters that are able to produce a sense of identification among viewers occurs fundamentally, and initially, through certain Latin-American prototypes. 


\section{The narrative roles of immigrants}

Once the plots in which immigrant characters appear had been identified, we applied an analytical methodology based on semiotic narrative, described in Section 5, with the aim of examining the image of immigration that Spanish produced television series project as well as the universe that is constructed around immigrant characters.

The narrative roles analyzed correspond to the following categories:

1. Performer of the action: the character that performs an action in order to achieve a certain objective.

2. Beneficiary of the action: the character that benefits from or is prejudiced by the acts of the Performer.

3. Mission-setter: the character that requires the Performer to seek out an objective.

4. Assistant: the character that helps the Performer to achieve his objective.

5. Opponent: the character that hinders the action of the Performer and makes it difficult for him to achieve his objective.

6. Rival: the character that strives for the same objective as the Performer of the action and is in competition with him.

7. Recognizer of the action: the character that, at the end of the plot, is either grateful for or critical of the Performer's action.

8. Objective: the thing that the Performer of the action wishes to achieve for himself or for another character.

Although 29 immigrant characters were found among the 41 plots analyzed, the total number of narrative roles enacted by immigrant characters was 86 . This is because a single character may perform several narrative roles in one plot.

The first significant results of the analysis provide general quantification of the narrative roles performed by immigrant characters.

As can be seen in the graph, immigrants appear in Spanish television series more than fifty percent of the time as beneficiaries of the main action in the plot or as the mission-setter for the performer. We should note that the missionsetter is a figure that often coincides with that of the beneficiary of the action (here in 15 of the 23 registers). The greatest relevance of both narrative roles appears in the initial stage of the plot where the narrative conflict is introduced: somebody wants or needs something, or somebody else thinks this thing would be good for them, and thus the action begins. Since the beneficiary of the main action of the performer is an "incomplete" character, and resolving the beneficiary's problems tends to be the performer's objective, it is significant how often immigrants are portrayed as characters with some kind of problem or need that stands out in the plot. In contrast, the presence of the immigrant as 


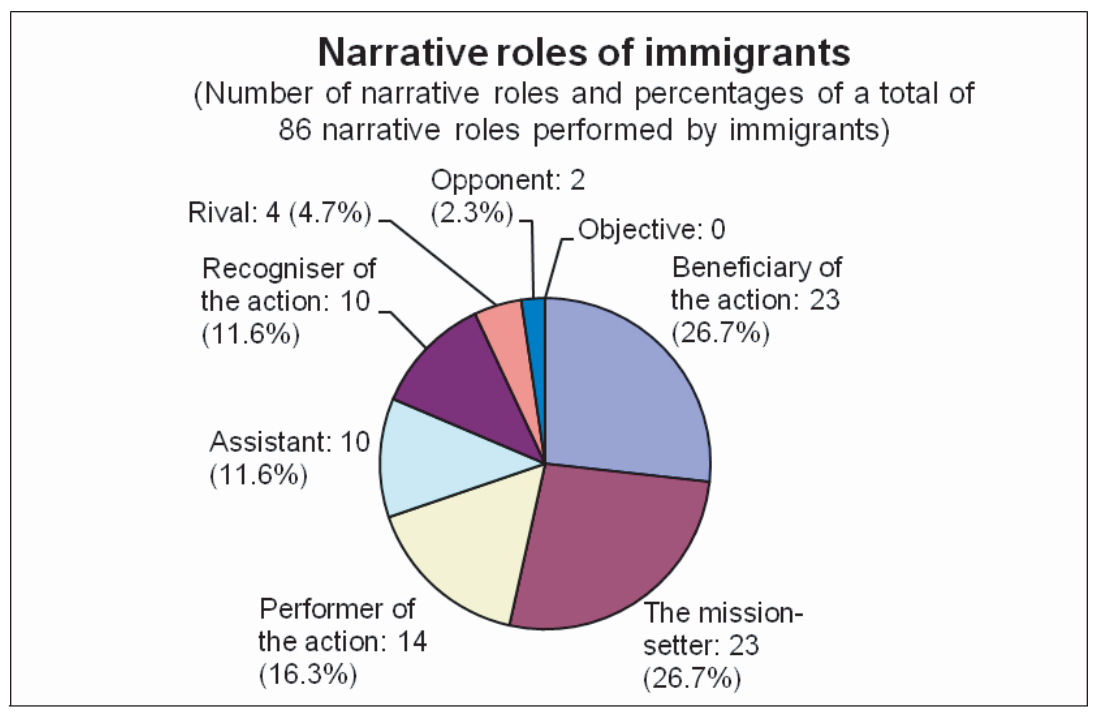

Figure 1. Narrative roles of immigrants in Spanish television series

performer of the action in the plots of Spanish television series is notably inferior.

The benefits most often assigned to the immigrant character (objectives with respect to the performer) are those relating to justice (revenge for an aggression or offence, discover a murderer, etc.), other reasons relating to survival (safety, protection, freedom), or some kind of socio-economic benefit (money, work), or legal (work or residence permit, for example).

Regarding the categories in which immigrants appear less frequently (objective, opponent, rival), it should be noted first that only on rare occasions is the objective - as a narrative category — enacted by a character, which normally occurs in plots of a romantic nature. Second, immigrants as opponents or rivals are very rare. Only 6 of 86 registers contain the immigrant as an opponent or rival, which means that the immigrant as adversary is practically non-existent in the plots of Spanish series analyzed. So, far from painting a picture of the immigrant as the enemy of the performer (usually embodied in a Spanish character), it seems that Spanish serialized fiction production tends to adopt a politically correct stance. Thus, immigrants may frequently be a cause of conflict due to a need for or a lack of some element (beneficiaries of the main action), but they never generate conflict intentionally themselves. The conclusion is that immigrants can cause problems but do not wilfully engage in confrontation.

Below, we identify the main traits that comprise the image of the immigrant character in television series, focusing on the most relevant narrative roles in 
which the figure of the immigrant appears: that of the beneficiary of the action and that of the performer of the action.

\subsection{Traits attributed to the immigrant as beneficiary of the action}

The narrative role of the beneficiary of the action takes the form of a character with some kind of problem or need in the plot and who, at the same time, tends to contemplate or induce another character to search a particular objective. For this reason, we jointly analyze here the traits assigned to the immigrant in the narrative roles of the beneficiary of the action and the mission-setter for the performer.

The recent massive flow of immigration to Spain might generate the perception of a situation of conflict between native Spanish people and the different groups of people arriving from elsewhere. The television series of nationwide channels clearly avoid presenting an image that reveals conflictive relationships. In this sense, it is noteworthy that on very few occasions do immigrant characters confront Spanish characters, either in competing for the same objectives or in order to directly hinder the Spanish performer.

While an image of conflict does not appear through confrontation between the immigrant and the Spanish character, the immigrant as beneficiary of the action does exhibit three recurring negative traits in relationships with Spanish people: the problem, the fabricator, and the victim.

3.1.1. The problem. In such cases, conflict and competition for the same objective, whether social, economic, institutional or romantic in nature, projects an image of immigrants as a group predisposed to gain some kind of advantage or value from Spanish characters. As noted previously, this image is not at all common in Spanish series. However, neither does the opposite image clearly appear, that of the immigrant community as one that contributes cultural, social or economic values to the receiving country. It is, therefore, significant that there are few immigrant performers of action that seek some kind of gain for the characters of Spanish origin. Also relevant is the fact that, in addition to the activities included in the service sector, many of the professional activities of the immigrants that appear in series are related to "show business" or with illegal activities. However, there are no immigrants in professional activities like building or agriculture, which would project an image of a beneficial productive effort in favor of the development of the country and where, in reality, immigrant presence is common.

Therefore, in general terms, it may be stated that immigrants in series do not detract from nor explicitly contribute to a plot. Nonetheless, a very common 
image in the plots of television series is that of the immigrant who, as beneficiary of the action, has needs and problems that a particular Spanish character solves through a demonstration of generosity and solidarity. Here the image of the immigrant as a problem appears. The immigrant is neither a usurper nor a benefactor, but in the dichotomy between being a driving force for development in Spanish society in different fields and being a problem, immigration tends to appear, in relative terms, as a problem.

3.1.2. The fabricator. In the plots of television series, the immigrant beneficiary of the action often appears as a character that resorts to manipulation and deceit when dealing with native Spanish characters. These Spanish characters often seem either naive, allowing themselves to be taken in, or they are people who are constantly alert for deception. Thus, we have the emergence of a very important element of problematic relationships between immigrant and native Spanish communities, which has fundamental effects on the degree of trust between them. It should be noted that relationships of trust are absolutely necessary to enable activities of cooperation between the two communities.

3.1.3. The victim. A recurrent theme is the portrayal of the immigrant beneficiary of the action as an individual with serious problems and indire circumstances that are the result of different factors, such as the situation in their home country, legal, institutional, and socio-economic barriers encountered in Spain, groups of a racist nature in Spain or international immigration mafias. In each case, the immigrant tends to appear as a victim, that is, someone whose negative situation is not the result of any wrong act of their own that could be considered reproachable. Accordingly, the immigrant appears as blameless, in the same way that all victims are innocent victims. However, in the plots of some television series, immigrant characters use their condition of victimhood, exaggerating it or transforming it to suit their convenience, in order to manipulate for their own benefit the Spanish character that has offered their solidarity.

In addition, in order to solve their problems and attend to their needs, the immigrant beneficiary of the action finds characters that give them their support or, in contrast, make it impossible for them to solve their problems. In most cases, the characters that support the immigrant and take on the task of meeting their needs are cast as Spanish people who act individually, in a private role, even though they act within the framework of a public institution. Thus, in the plots of television series, it is quite common to find Spanish characters that are generous, predisposed, intelligent, and who act in solidarity with and for the benefit of the immigrant. The negative position is almost always 
transferred from the individual and private context to the abstract and collective sphere. In this way, the characters that cause the immigrants problems and hinder solutions to the problems are abstract characters like social norms and institutions and the laws that affect immigrant groups, and also group characters such as Spanish racist groups or international immigration mafias. Therefore, there is a certain tendency to project an image that, when described in direct, graphic terms, responds to the following assumption: Spanish people are good, the "system" is bad.

Also worthy of note is the fact that there is no significant presence of solidarity among the immigrants themselves, except in some cases where the motive is a family relationship, love or friendship. Even more relevant is the lack of support from immigrant social organizations. This fact means that immigrants are portrayed as isolated individuals that solve their problems alone and are incapable of generating support structures through their own social organizations. Such associations already exist in Spain, although they are still probably at an embryonic stage of development. It is interesting that this fact is not reflected in television series, while reference is recurrently made to illegal and criminal organizations such as immigrant mafias and white-slave trading of foreign women, etc.

\subsection{Traits attributed to the immigrant as the performer of the action}

In all narrative plots, the characters may possess all kinds of features, depending on the role they adopt. The main character or prototypical hero possesses the following qualities: centrality, action, independence, effectiveness, and positivity.

3.2.1. Centrality. The central narrative roles in a plot are fundamentally: the performer of the action, the beneficiary of the action, and also, occasionally, the rival who confronts the main character, competing for the same objective. More peripheral roles are that of the character that induces the main character to act, the individuals that help or hinder the main character's mission, and the character that eventually expresses gratitude or dissatisfaction with the acts performed by the main character.

In the plots in which they appear, immigrants tend to occupy a central position basically as beneficiaries of the action developed in the plot and, to a lesser extent, as performers of the action. The peripheral position that the immigrant most often occupies is that of the character that induces the performer to act - generally a Spanish character. 
3.2.2. Action. A prototype of a hero is a character that aims to fulfill a mission. In this sense, the immigrant characters that appear in series cannot generally be classified as performers of the action.

3.2.3. Independence. A character's independence is based on their capacity to take on and carry out missions for their own good or for the good of others. In contrast, a dependent character needs others to do things for them. In this sense, the immigrant is portrayed as dependent in the majority of cases.

3.2.4. Effectiveness. An effective character is one that develops an action with a particular objective in mind and successfully achieves that objective. This action may be a principle one, an action that induces the main character to act or an action that helps the main character.

Generally, the figure of the immigrant has an ineffective image. Very few plots involve the immigrant achieving what they have proposed for themselves or for others and, in any case, where they are more effective is in actions designed to induce others to act in their benefit.

3.2.5. Positivity. This is a trait defined by the nature of the character, by the ethical and social values that are reflected in the objectives they pursue, and the means and actions they employ to achieve these objectives, whether they be socio-economic, institutional, experiential, romantic, etc. In general, the immigrant characters that appear in series as performers of the action do not pursue objectives that are unethical or socially negative. However, they do tend to use strategies that involve deceiving other people, usually Spanish characters.

In general, we observe that the immigrant character is denied the image of main character or outright hero. When appearing as an active character, however, they are ineffective and negative in developing their plans of action. Nevertheless, when the character is active and independent, the role played is not central to the structure of the narrative plot. When it is effective, it is also dependent. In fact, the figure of the immigrant is very often portrayed as effective in a state of dependence. Finally, when an immigrant character is positive, it is also ineffective.

This lack of a complete image of the immigrant as performer or hero of the action contrasts with the image that the same plots project of many Spanish characters, who do appear simultaneously as central, independent, active, effective, and positive. 


\section{Conclusions}

In conclusion, the results of this study present a group of five narrative structures that recur in immigrant characters. In addition, we may make certain basic observations about the communicative management of the social image of the immigrant, which we address in the following section of this paper.

\subsection{Prototypical narrative structures}

To answer the central question of what narrative universe is constructed around immigrant characters, we analyzed the most frequent recurring features of the plots chosen for the sample. This approach yielded five prototypical narrative structures that concentrated on the most frequent characteristics, actions, fictional worlds, and values associated with the immigrant character in television series.

We present these structures in order according to their specific weight. Therefore, the two prototypical narrative structures relating to the most frequent narrative role of the immigrant, that is, as beneficiary of the main character's action, are presented first. Next are the two narrative structures in which the immigrant acts as main character of the plot and, finally, the narrative structure in which the immigrant plays a peripheral role as an assistant to the main character.

\subsubsection{The immigrant as beneficiary of the main character's action}

4.1.1.1. The epic of the Spanish character as fair, good, and sympathetic. A young, sometimes adolescent Spanish character that is responsible and sympathetic acts as a friend or someone in the public sector, or persuades some other Spanish character to act, in favor of an immigrant or immigrant community - usually a family or a group of friends - to ensure that justice is done, to get revenge, to refute a false accusation, to discover a murderer or to obtain some kind of socio-economic benefit.

The main obstacles to achieving the mission lie in the law, in the racist culture of some Spanish groups or in problems that originated in the immigrant's home country.

Whatever the case may be, the Spanish character that takes on the positive mission for the immigrant is successful and achieves his objective.

4.1.1.2. The Spanish character responds to the call of the immigrant. A male or female Latin-American immigrant - young, seductive, crafty, and 
manipulating - gets a young, generous, and sympathetic male or female Spanish character that works in the public sector (in a hospital, as a police officer, etc.) to take on the mission of providing them with greater security, freedom, and protection, or some kind of legal or financial benefit.

In carrying out the mission, another Spanish character that is a workmate of the main character also helps. However, the mission is hindered either by a group of intolerant, racist Spanish people or by laws or restrictive legal regulations affecting the rights of immigrants.

Finally, the immigrant thanks the dedication of the Spanish character in acting to achieve some benefit.

\subsubsection{The immigrant as performer of the action}

4.1.2.1. The great deceiver. A young, attractive male or female LatinAmerican immigrant with a sentimental attachment to a Spanish character is in need of some kind of socio-economic or romantic benefit and uses deceit, seduction or manipulation to obtain it.

In a romantic context, they are confronted with possessive Spanish characters, and in a professional context, which occurs less frequently, the obstacle is the Spanish authorities - bosses, laws or police and judicial institutions. The immigrant does not tend to find help, and, if they find it, it is by chance.

However, thanks to their skill in deception, seduction, and manipulation, they almost always achieve what they set out to do although, on occasion, a jealous partner or some Spanish authority eventually reproaches them for their deception.

4.1.2.2. The feared initiative of the immigrant with good intentions. A young, extroverted, seductive, black or mulatto Cuban male attempts to put right or avoid some loss or harm suffered or to be suffered by his partner or friend. In a gesture of sympathy, the immigrant acts in haste even though nobody has asked him to do so and despite the fact that the only help he receives comes from relatives.

As someone who lives or has lived in an illegal environment, sooner or later he comes face to face with one Spanish authority or another, mainly bosses and laws, in such a way that when he acts in favor of other immigrants, he always fails and when he acts in favor of a Spanish character, he may equally fail or succeed.

4.1.3. The immigrant as assistant to the main character: The tragicomedy of the big-hearted vigilante. A black immigrant with a kind nature, extroverted, 
generous, friendly (if a man) or a mulatto with a negative temperament, restless, insecure, fearful (if a woman) acts in good faith to help a young white Spanish character, with whom they have a personal relationship, with a view to assuming the actions of public Spanish institutions or to compensating for some inequality or social injustice.

The immigrant acts in a private capacity and the actions they perform are good or are for a good cause although, at times, the person receiving their help has negative motives.

The immigrant who helps the Spanish character encounters opposition both in the form of violent, racist, white Spanish people and from other immigrants.

Despite good intentions, the immigrant's efforts turn out to be fruitless in most cases and, thus, they appear incapable of helping their Spanish friends in difficulty by assuming functions that normally correspond to public bodies.

\subsection{Communicative management of the immigrant's social image}

This study considers the importance of television fiction in the process of creating images and social prototypes that influence the way that the public perceives, contemplates, and experiences social reality. This may affects the construction of the public image of the immigrant and the problems deriving from the process of immigration.

Television fiction series in Spain may not directly foment racist or xenophobic values that might be incubating in the heart of Spanish society. However, as the results of our study show, there are data to suggest that there is reason for concern and reflection. For example, why do some channels directly ignore the presence of immigrants in their fictitious worlds? What problem exists regarding the figure of the North-African (Maghribian) in Spanish society that makes it practically non-existent in the fictional television series of nationwide channels?

Also, there are certain values that are projected in these television series regarding immigrants that neither facilitate their integration into Spanish society nor instill a positive attitude in Spanish people towards them. We may clearly state that, depending on the images conveyed and the narrative structures employed, the Spanish viewer will acquire an attitude of distrust towards immigrants: immigrants tend to be ineffective; they are not capable of achieving the objectives they set themselves; they have a propensity for fabrication, manipulation, and deceit. As a result, one cannot trust in the effectiveness of an immigrant's actions nor believe what they say. As previously noted, a common, collective project involving immigrants and Spanish people must be based on a relationship of mutual trust. The construction of this possible and desirable 
relationship could be negatively affected by the collective images that television series project.

The appropriate management of the image of immigration in Spain therefore requires a continuous questioning and analysis of fictional content that is conveyed through the mass media, an analysis that goes beyond the superficial and evident, and which examines the underlying structures and values that are of great importance in the construction of the images of immigration that are generated in our society.

\section{Methodological contributions by X. Ruiz Collantes. Analytical matrix: Structure and functions}

\subsection{Introduction}

The aim of this study was to analyze the image of immigrants that is projected in series produced by Spanish television companies.

Adopting a methodological approach to this task requires resolving a contradiction between two significant issues: first, the size of the sample, which entails analyzing a corpus consisting of 41 narrative plots comprising 676 broadcasting minutes; and second, the attempt to obtain results that involve complex analytical units of a narrative nature and not merely thematic or lexical-iconic-conceptual units.

We have used the theoretical and methodological categories associated with semiotic narrative, of Greimasian $(1973,1989,1990)$ origin. The criterion for using semiotic narrative is that the study of the image of a character type in narrative texts can only be conducted effectively if we take into account the role that the character plays in the narrative structure that is built in the text.

In general, there are two types of text content analyses: intensive-qualitative and extensive-quantitative.

Intensive analyses focus on limited corpora - advertising spots, poems, paintings, etc., or wider sources: novels, films, etc. This type of analysis is common in semiotic narrative and, within this theoretical framework, provides a thorough study of all the levels of the generative flow of the text analyzed, from the most superficial to the deepest, from the discursive to the axiological, from the enounced to the enunciated (from énonciation to énoncé). Most levels are examined in order to explore the underlying values and meanings. This type of analysis is merely qualitative and the interpretive inclinations of the analyst play an important part at all times.

Extensive analyses focus on large corpora, applying some criterion to form a coherent object of study. In these cases, quantitative methods tend to be used, such as those employing content analysis techniques that focus on counting 
lexical units or methods such as agenda setting, which contemplate thematic units. Extensive analyses normally base quantification on techniques that are, as far as possible, susceptible to being replicated by different subjects, and so, are not subject to the interpretation of each individual.

The objective of the methodological design employed in this study is to combine an extensive analysis, which contains a quantitative component in its development, with an analytical methodology, semiotic narrative, which is eminently qualitative in nature.

The methodological strategy of the study consists in examining the audiovisual texts analyzed in order to define the levels of their configuration that are most relevant to achieving the aims of this study. For this reason, we have not studied every one of the text levels of the plots analyzed. Only a small number of them were chosen, the same for all units analyzed in order to always consider the same group of items. This approach ensures the homogeneity of the process and of the results.

In accordance with these objectives, the analysis focuses on specific components of the two text levels: the semionarrative level and the discursive level.

At the semionarrative level, we analyze the distribution of the actantial position of the different characters for each plot. On the analytical scale of each of the plots studied, an immigrant occupies one or more positions within the actantial structure while the remaining positions are occupied by other types of actors. In this way, the scale of actantial structures of all the plots eventually make it possible to study the most frequent actantial roles played by actorimmigrants, other types of actors they interact within the basic narrative frameworks, the most frequent positions that these types of actors occupy, and the narrative relationships the different types of actors establish among themselves.

For the analytical scale at the discursive level of each plot we take into account: the different actors that take part; their physical and social characteristics, personality, and passional figures; the physical and social places and time periods of the setting and interaction; and the types of actions and interactions that the actors are involved in. Thus, the final scale extracted from the total number of plots shows results relating to characteristics most frequently observed for each type of actor, the spatial-temporal dimensions in which they most frequently appear, the most reiterative actions that they perform and the most common passions and beliefs that motivate them.

The analytical matrix employed in this study was designed using the actantial structure as the foundation for the organization of the data compiled, so that the discursive level components are organized according to that actantial structure. This matrix design makes it possible to preserve the narrative structure in the register template of the data collected. The analytical matrix can be consulted in the next section. 
The structures in the data register and the results directly derived from them identify narrative frameworks with a high degree of abstraction, frameworks in which the details of the most superficial levels of the audiovisual texts analyzed have been eliminated. In this way, we obtain a clear insight into the reiterative components of the deepest levels of the narrations. These components provide a relevant answer to the initial question raised in this research: What is the image of immigrants that is projected in Spanish television series?

However, the analytical registers of the plots studied may not merely result in a quantification of the actantial positions of the various types of actors or the specific characteristics thereof. On the contrary, adhering to the principle of "belonging" in narrative texts, the results must also shed light on the prototypical narrative structures.

We define a prototypical narration as a narrative framework constituted by the common characteristics of a number of narrations that, following certain criteria and at specific levels of their configuration, seem alike and form a homogeneous group.

The basis for a prototypical narration is a group of narrative structures that are similar in the way in which specific types of actors are distributed around the core of the different actantial positions. The prototypical narration is derived from this initial group of narrative structures and is constructed using the common characteristics of those structures.

To define the prototypical narration, the register of the common characteristics of the different base narrations is constructed on a generalizationparticularization axis, favoring, where possible, the most outstanding common characteristics. An example of this is a prototypical narration that is defined by the fact that, in different narrations, immigrants occupy the actantial position of the subject of action (performer of the action). If the different immigrants in the different narrations have no other common characteristic except that of being an immigrant, the prototypical narration would begin as follows: "an immigrant performs an action with the aim of . . " However, a different case is where, among the immigrants in the base narrations, several common characteristics are registered or where the characteristics are common to a great extent. These characteristics would appear in the prototypical narration that could begin, for instance, as follows: "a young male Latin-American immigrant engages in verbal communicative interactions with the aim of ..." The first example is a case of a prototypical narration with a higher degree of generalizationabstraction, while, in the second case, the prototypical narration has a higher degree of particularization-concreteness.

Defining prototypical narrations is essential because it makes it possible to identify underlying reiterative, relevant narrative frameworks in the extensive and varied repertory of the narrations that are the object of this study. 
A prototypical narration may not necessarily correspond to a particular narration in the sample of narrations analyzed. It is, therefore, a construct resulting from an analytical process. Nevertheless, we may state the hypothesis that it acts as a framework with a particular identity in the process of text construction, like a basic cognitive narrative layout for creating a particular type of narration. Furthermore, cognitively, a prototypical narration may correspond to frameworks of a narrative character that form and settle in the minds of the receivers through a plural and disperse group of narrations. Thus, for example, the prototypical narratives about immigrants that underlie the plots of Spanish television series could possess the same cognitive characteristics as those of the prototypical categories defined by the theory of prototypes in cognitive psychology.

This study uses the categories of semiotic narrative on which to base its protocols of analysis. However, at the same time, criteria have been established for an extensive study of a very wide corpus of texts. The results of such a study should inform the underlying reiterative, relevant narrative universes in the defined corpus and the values and meanings that exist in these universes.

Two fundamental premises in the design of the methodological apparatus have been adopted in order to ensure meaningful results:

1. The same analytical criteria were applied to all of the audiovisual texts so as to minimize the heterogeneity of the interpretive factor.

2. The data obtained on the group of plots analyzed were stored using a versatile computerized compilation system that allowed all information to be fully utilized.

For this research we have designed an analytical matrix based on the methodological premises described. To use this template effectively, it is necessary to define, implement, and employ a computer programme that can store, organize, and compare information in a flexible manner.

There are four fundamental phases for the use of this analytical matrix:

1. Each narrative plot is analyzed using the categories established. After studying each narrative unit, the matrix is filled in so as to reflect the deep structure of the unit.

2. The data compiled on the group of narrative plots is stored on a computer system specially designed for the purpose.

3. The questions to which answers are required are determined and organized and, to this end, the information stored on the computer system is employed.

4. The data obtained is analyzed and conclusions are drawn.

The methodological model applied can be replicated in its various phases by other researchers without the danger of an interpretive factor causing any rel- 
evant changes in the results obtained. This is so not only with regard to the actantial positions and the characteristics of the different actors but also to the prototypical narrations identified.

In addition, the methodological model designed can be conveniently adapted for use in other areas of study unrelated to the present research.

\subsection{Analytical matrix}

\author{
ANALYSIS UNIT IDENTIFICATION \\ 1. Unit number \\ 2. Analyst number \\ 3. Analysis data \\ 4. Fiction product ID number
}

ANALYSIS PLOT IDENTIFICATION

1. Analysis unit (plot)

2. Number of plots (total)

3. Type of plot
a) Principal
b) Secondary

4. Number of scenes (plot)

5. Plot duration (total)

6. Plot summary

7. Key word identification
a) Principal theme / keywords
b) Actors / keywords
c) Actions / keywords
d) Territorial areas / keywords

NARRATIVE ROLES

A. PERFORMER OF THE ACTION (SUBJECT, HERO)

1. TYPES

a) Type 1
I. Individual
II. Collective

b) Type 2
I. Figurative
II. Abstract

c) Type 3

I. Supernatural element / specify

II. Natural element / specify
III. Artefact / specify

IV. Human individual or groups / specify

V. Cultural elements / specify

d) Public

I. Political-institutional / specify

II. Social / specify

e) Private

I. Professional / specify

II. Personal / specify

\section{CHARACTERISTICS}

a) Physical features, age and gender / specify

b) Character: ethical, passionate, cognitive / specify

c) Origin / specify

3. COMPETENT FOR THE ACTION

a) Want

I. Yes (explicit / assumed)

II. No (explicit / assumed)

b) Have to

I. Yes (explicit / assumed)

II. No (explicit / assumed)

c) Can

I. Yes (explicit / assumed)

II. No (explicit / assumed)

d) Know

I. Yes (explicit / assumed)

II. No (explicit / assumed)

\section{PASSIONS AND BELIEFS}

Driven to act by:

a) Passions / specify

b) Beliefs / specify 


\section{ACTION SPACES AND TIME}
a) Spaces / specify
b) Times / specify

\section{ACTIONS/TRANSFORMATIONS}

a) Aimed at:
I. Making someone win an object
II. Making someone lose an object
III. Maintaining possession of an object
IV. Maintaining lack of an object

b) Type of action

I. Material-somatic/specify

II. Cognitive/ specify

III. Communicative / specify

IV. Institutional / specify

c) Action sphere

I. Public

i) Political-institutional / specify

ii) Social / specify

II. Private

i) Professional / specify

ii) Personal / specify

\section{B. BENEFICIARY OF THE ACTION}

1. TYPES

a) Type 1

I. Individual

II. Collective

b) Type 2
I. Figurative

II. Abstract

c) Type 3

I. Supernatural element / specify

II. Natural element / specify

III. Artefact / specify

IV. Human individual or groups / specify

V. Cultural elements / specify

d) Public

I. Political-institutional / specify

II. Social / specify e) Private

I. Professional / specify

II. Personal / specify

\section{CHARACTERISTICS}
a) Physical features, age and gender / specify
b) Character: ethical, passionate, cognitive / specify
c) Origin / specify

\section{ACTION SPACES AND TIME}
a) Spaces / specify
b) Times / specify

\section{OBJECT}

1. Existential / specify

2. Social/economic/specify

3. Ethical/political/specify

4. Passionate / specify

5. Cognitive / specify

6. Abilities to act and achieve objectives
a) Want
b) Have to
c) Know
d) Can

\section{ASSISTANT}

1. TYPES

a) Type 1

I. Individual

II. Collective

b) Type 2
I. Figurative

II. Abstract

c) Type 3
I. Supernatural element / specify
II. Natural element / specify
III. Artefact / specify
IV. Human individual or groups / specify
V. Cultural elements / specify

d) Public
I. Political-institutional / specify
II. Social / specify 
e) Private

I. Professional / specify

II. Personal / specify

2. CHARACTERISTICS
a) Physical features, age and gender / specify
b) Character: ethical, passionate, cognitive / specify
c) Origin / specify

3. BENEFITS OF THE AID ACTION
a) Existential / specify
b) Social/economic / specify
c) Ethical/political / specify
d) Passionate / specify
e) Cognitive / specify
d) Abilities to act and achieve objectives
I. Want
II. Have to
III. Know
IV. Can

\section{AID ACTION}

a) Aimed at:

I. Making someone win an object

II. Making someone lose an object

III. Maintaining possession of an object

IV. Maintaining lack of an object

b) Type of action

I. Material-somatic / specify

II. Cognitive/ specify

III. Communicative / specify

IV. Institutional / specify

c) Action sphere

I. Public
i) Political-institutional / specify
ii) Social / specify

II. Private
i) Professional / specify
ii) Personal / specify

\section{E. OPPONENT}

1. TYPES

a) Type 1

I. Individual

II. Collective

b) Type 2

I. Figurative

II. Abstract

c) Type 3

I. Supernatural element / specify

II. Natural element / specify

III. Artefact / specify

IV. Human individual or groups / specify

V. Cultural elements / specify

d) Public

I. Political-institutional / specify

II. Social / specify

e) Private

I. Professional / specify

II. Personal / specify

2. CHARACTERISTICS

a) Physical features, age and gender / specify

b) Character: ethical, passionate, cognitive / specify

c) Origin / specify

3. HARM IN THE OPPONENT'S ACTION

a) Existential / specify

b) Social/economic / specify

c) Ethical/political / specify

d) Passionate / specify

e) Cognitive / specify

d) Abilities to act and achieve objectives

I. Want

II. Have to

III. Know

IV. Can 


\section{OPPONENT'S ACTION}

a) Aimed at:

I. Making someone win an object

II. Making someone lose an object

III. Maintaining possession of an object

IV. Maintaining lack of an object

b) Type of action

I. Material-somatic / specify

II. Cognitive/ specify

III. Communicative / specify

IV. Institutional / specify

c) Action sphere

I. Public
i) Political-institutional / specify
ii) Social / specify

II. Private

i) Professional / specify

ii) Personal / specify

\section{F. CONTRACT (THE MISSION-} SETTER)

\section{TYPES}

a) Type 1

I. Individual

II. Collective

b) Type 2

I. Figurative

II. Abstract

2. INTERNAL WITHIN THE SUBJECT (HERO)

a) Type

I. Psychological features / specify

II. Ethical values / specify

III. Passions / specify

IV. Beliefs / specify

V. Instincts / specify

VI. Others / specify

b) Contractual manipulation

I. Promise/ specify

II. Threat/ specify
III. Seduction / specify

IV. Provocation / specify

c) Effect of contractual manipulation

I. To make someone want (provoke desires) / specify

II. To make someone have to (provoke obligations) / specify

d) Action spaces and times

I. Spaces / specify

II. Times / specify

\section{EXTERN TO THE SUBJECT} (HERO)

a) Types

I. Public

i) Political-institutional / specify

ii) Social / specify

II. Private

i) Professional / specify

ii) Personal / specify

b) Characteristics

I. Physical features, age and gender / specify

II. Character: ethical, passionate, cognitive / specify

III. Origin / specify

c) Ability for the action

I. Want

i) Yes (explicit / assumed)

ii) No (explicit / assumed)

II. Have to

i) Yes (explicit / assumed)

ii) No (explicit / assumed)

III. Can

i) Yes (explicit / assumed)

ii) No (explicit / assumed)

IV. Know

i) Yes (explicit / assumed)

ii) No (explicit / assumed)

d) Passions and beliefs

Driven to act by:

I. Passions / specify

II. Beliefs / specify 
e) Contractual manipulation

I. Promise / specify

II. Threat / specify

III. Seduction / specify

IV. Provocation/ specify

f) Effect of contractual manipulation

I. To make someone want (provoke desires) / specify

II. To make someone have to (provoke obligations) / specify

g) Action spaces and times

I. Spaces / specify

II. Times / specify

G. SANCTION (RECOGNISER OF THE ACTION)

1. TYPES

a) Type 1

I. Individual

II. Collective

b) Type 2

I. Figurative

II. Abstract

c) Type 3

I. Supernatural element / specify

II. Natural element / specify

III. Artefact / specify

IV. Human individual or groups / specify

V. Cultural elements / specify

d) Public

I. Political-institutional / specify

II. Social / specify

e) Private

I. Professional / specify

II. Personal / specify

2. CHARACTERISTICS
a) Physical features, age and gender / specify
b) Character: ethical, passionate, cognitive / specify
c) Origin / specify

\section{COMPETENT FOR THE ACTION}

a) Want
I. Yes (explicit / assumed)
II. No (explicit / assumed)

b) Have to

I. Yes (explicit / assumed)

II. No (explicit/ assumed)

c) Can

I. Yes (explicit / assumed)

II. No (explicit / assumed)

d) Know
I. Yes (explicit / assumed)

II. No (explicit / assumed)

\section{PASSIONS AND BELIEFS}

Driven to act by:
a) Passions / specify
b) Beliefs / specify

5. ACTION SPACES AND TIME
a) Spaces / specify
b) Times / specify

6. SANCTION

Types of sanction

a) Recognition

I. Positive / specify

II. Negative / specify

b) Retribution

I. Prize / specify

II. Punishment / specify

H. RIVAL (ANTISUBJECT)

1. TYPES

a) Type 1

I. Individual

II. Collective

b) Type 2

I. Figurative

II. Abstract

c) Type 3

I. Supernatural element / specify

II. Natural element / specify

III. Artefact / specify

IV. Human individual or groups / specify

V. Cultural elements / specify 
d) Public

I. Political-institutional / specify

II. Social / specify

e) Private

I. Professional / specify

II. Personal / specify

2. CHARACTERISTICS

a) Physical features, age and gender / specify

b) Character: ethical, passionate, cognitive / specify

c) Origin / specify

3. COMPETENT FOR THE ACTION

a) Want

I. Yes (explicit / assumed)

II. No (explicit / assumed)

b) Have to

I. Yes (explicit / assumed)

II. No (explicit / assumed)

c) Can

I. Yes (explicit / assumed)

II. No (explicit / assumed)

d) Know

I. Yes (explicit / assumed)

II. No (explicit / assumed)

\section{PASSIONS AND BELIEFS}

Driven to act by:

a) Passions / specify

b) Beliefs / specify

5. ACTION SPACES AND TIME

a) Spaces / specify

b) Times / specify

\section{ACTIONS/TRANSFORMATIONS}

a) Aimed at:

I. Making someone win an object

II. Making someone lose an object

III. Maintaining possession of an object

IV. Maintaining lack of an object

b) Type of action

I. Material-somatic/specify

II. Cognitive/ specify

III. Communicative / specify

IV. Institutional / specify

c) Action sphere

I. Public
i) Political-institutional / specify
ii) Social / specify

II. Private
i) Professional / specify
ii) Personal / specify

\section{FINAL STATES}

1. Relation between Beneficiary and object
a) Conjunction
b) Disjunction

2. Relation between Subject (hero) and object
a) Success
b) Failure

\section{Note}

* This project was undertaken in the Department of Journalism and Audiovisual Communication of Pompeu Fabra University by the UNICA group (Research Unit on Audiovisual Communication) and was financed by the Ministry of Science and Technology. 


\section{References}

Greimas, Algirdas J. 1973. En torno al sentido. Ensayos semióticos. Madrid: Fragua.

Greimas, Algirdas J. 1989. Del sentido II. Ensayos semióticos. Madrid: Gredos.

Greimas, Algirdas J. 1990. Narrative semiotics and cognitive discourses. London: Pinter.

Xavier Ruiz Collantes (b. 1957) is a professor at Universitat Pompeu Fabra <xavier.ruiz@upf. edu $>$. His research interests include audiovisual discourse analysis, semiotics and advertising, and political discourse analysis. His publications include Retórica creativa: programas de ideación publicitaria (2000); "Presencia, discurso e imagen de los candidatos en las cadenas de televisión" (with E. Pujadas \& O. Pérez Latorre, 2007); and "Juegos y videojuegos. Formas de vivencias narrativas" (2008).

Matilde Obradors (b. 1957) is a professor at Universitat Pompeu Fabra <matilde.obradors@upf. edu $>$. Her research interests include the creative process, the construction of persuasive messages, analysis of strategies of communication, and semiotics analysis. Her publications include "Una aproximación al cine catalán desde el estudio de su proceso creativo" (2004); "Abrazar la existencia. Territorios de 'realidad' y territorios de 'ficción' en la creación cinematográfica" (2005); "El director de campaña como artífice del marketing político, la relación mediática y la trastienda electoral. Un estudio de caso" (with C. Pont, 2006); and "Los partidos en campaña: planteamientos, recursos y estrategias" (with C. Pont et al., 2007).

Eva Pujadas (b. 1968) is a faculty vice-dean at Universitat Pompeu Fabra <eva.pujadas@upf. edu $>$. Her research interests include television discourse, television quality, and television diversity. Her publications include "Formas narrativas y nuevos pactos ficcionales. Redefinición de los límites de la comunicación audiovisual. El caso de los talk shows y los reality shows" (2007); and "Analizar la diversidad de la programación televisiva. Identificación de dimensiones y construcción de indicadores" (2008).

Joan Ferrés (b. 1947) is a lecturer at Universitat Pompeu Fabra <joan.ferres@upf.edu>. His research interests include audiovisual communication and education, audiovisual competence, and audiovisual communication and the emotional brain. His publications include Educar en una cultura del espectáculo (2000); "La competencia en comunicación audiovisual: propuesta articulada de dimensiones e indicadores" (2006); "La educación en comunicación audiovisual en la era digital" (2006); and La educación como industria del deseo. Un nuevo estilo comunicativo (2008).

Óliver Pérez (b. 1980) is an assistant professor at Universitat Pompeu Fabra <oliver.perez@upf. edu $>$. His research interests include audiovisual discourse analysis, new forms of audiovisual narrative, semiotics and ludology, and videogame theory. His publications include "Presencia, discurso e imagen de los candidatos en las cadenas de televisión" (with X. Ruiz Collantes and E. Pujadas); "El bucle del arrepentimiento. Sobre la construcción del universo de ficción en Perdidos" (2007); and "Jugar a científicos: Videojuegos y divulgación científica" (2008). 
Copyright of Semiotica is the property of De Gruyter and its content may not be copied or emailed to multiple sites or posted to a listserv without the copyright holder's express written permission. However, users may print, download, or email articles for individual use. 